\title{
Taste Laws in Color Wheel and its Impact on Food Packaging
}

\section{Mehran Fateminia ${ }^{1^{*}}$, Talayeh Dehghani Ghotbabadi ${ }^{2}$ and Kamran Mohammadi Azad ${ }^{3}$}

${ }^{1}$ Department of Industrial Design, University of Tehran, Iran

${ }^{2}$ Department of Industrial Design, University of Science and Technology, Iran

${ }^{3}$ Department of Industrial Design, Art University of Isfahan, Iran

\begin{abstract}
Food color may change people's perception of their taste, by affecting the quality of taste. Because the taste of colors is related to people's mentality and presuppositions and refers to everyone's personal experience. Therefore, it is an acquired phenomenon. There is a meaningful correlation between taste and color. So, this research area needs an extensive study to reach general rules by considering a wide range of people with different experiences and mentalities. In this study, a statistical population was questioned for 11 general colors in food packing. After analyzing questionnaires data, significant correlations were obtained from matching the taste of colors with Itten colors cycle. It was demonstrated that most people identify secondary colors as color tonality, and the taste of complementary colors is felt and distinguished according to the intensity of their constitutive primary colors. For the second time questions about the tonality of colors such as green, orange and purple were asked, and the result matched with the Itten color rules. It was concluded that as colors have a set of basic rules, these rules also apply to the taste of each color, and perception of the color of each taste has a significant impact on food packaging.
\end{abstract}

Keywords: Food packaging; Color wheel; taste; People’s perception

\section{Introduction}

\section{Different viewpoints on the taste of colors}

In the nineteenth century, studies on visual traits such as color, demonstrated a different correlation concerning taste. Most of the researches conducted in this area were done on the basis of the effect of color on smell perception. Since smell and taste are almost located along each other, the results derived from smell by experiments are even consistent with color and taste. Similar stimulus traits were reported for interactions between smell and taste $[1,2]$. In some studies, it is directly expressed that visual signs such as food color may change people's perception of food's taste by affecting the taste quality of food [3].

On the other hand, it should be mentioned that taste, olfactory sense and sight directly help the perception of taste and smell, but what is usually first perceived is sight and then smell and taste, and this happens quickly. In a study [4], smell and taste of drinks with irrelevant colors were mistakenly identified by the participants. In other experiments by Posner et al. [5] and Parton Marler [6], the volunteers often dominated what could be classified and identified as the visual response. Herein the opponents of this theory mention that color has no relationship with smell and taste of drinks and food, and that the results obtained are not acceptable [7-10].

In contrast, there is strong physiologic evidence that claim visual signs can affect people's perception of smell type and intensity [11-17].

\section{Factors affecting identification of taste and color}

Describing fundamental relationships between color and senses is very difficult due to the various sense attitudes. In different researches, there are differences in identification of color related to gender. For instance, the studies of Guilford and Smith showed that women have higher awareness of color and their preferences in color selection are more varied. Dorcus also stated that yellow has a higher emotional value for men in comparison with women $[18,19]$, while the studies of Ou et al. [18], did not show any differences in perception and identification of feelings between men and women. Neither did Saccucci find a significant difference between comprehension and identification of tastes related to gender [20]. Researches show that the variation in identification and selection of colors depends on age [21,22]. In another study, Hutchings mentioned that selection and identification of color is determined by means of evolution [23].

In many studies, color traits such as value, hue and chroma were discussed and their effects on selecting favorite colors for a product were studied. According to Arnheim's studies, the correlation between favorite colors and color traits is still unknown. Nevertheless, selecting color for non-food products is often based on graphic techniques and ways in which people want to show them [24]. In this case, color affects the appearance of products; as Hutchings has found a significant correlation between appearance of food with overview of food color and appearance traits which indicates the importance of food appearance in every part of industry [23].

\section{Applied methods}

Methods of evaluating the effects of color on taste are different in many researches. The influence of taste is reported by questioning the change in color set or by using color and chemical solution and drinks by several Researchers [4,8,16,25-28]. In these studies, it was mentioned that the influence of the quality of colors can be demonstrated in numerous experiments with different levels of chroma and saturation $[18,28]$. While Zajonc [29] indicates that these two factors have no role in identification and selection processes and only the name of each color can be used as the representative of each color group.

\section{Research questions}

The most effective aspects in specific color category are the symbolic

*Corresponding author: Mehran Fateminia, Department of Industrial Design, University of Tehran, Iran, Tel: +98 21 61113411; E-mail: me.fateminia@ut.ac.ir

Received April 06, 2018; Accepted June 30, 2018; Published July 04, 2018

Citation: Fateminia M, Ghotbabadi TD, Azad KM (2018) Taste Laws in Color Wheel and its Impact on Food Packaging. J Food Process Technol 9: 739. doi: 10.4172/2157-7110.1000739

Copyright: (c) 2018 Fateminia M, et al. This is an open-access article distributed under the terms of the Creative Commons Attribution License, which permits unrestricted use, distribution, and reproduction in any medium, provided the original author and source are credited. 
and figurative relations of color with beliefs, which are perceived by the five senses and lead to identification [30]. Studies about the reaction of human to colors and the fundamental relationship between people's senses in identification and perception of colors are rare. People and even experts use color in different themes of product and space design as a factor for eliminating physical needs. Lack of attention to the interaction between color and human's psychological needs has hindered creativity in work themes and made the comprehension of emotional and functional connection with colors in products and spaces difficult for people. Color, in addition to being perceived by sense of sight, has a direct correlation with senses of taste and olfaction. It is even effective in perception of taste. Thus, color and taste are two basic factors affecting food acceptance. Studies show that people normally consider certain foods with certain colors and when the color of these products is changed on purpose, their perception will be reduced [31-34].

For example, someone's favorite color is blue, and his favorite food is hamburger, but a blue hamburger never attracts him even if it is delicious. Therefore, people's favorite colors do not cause interest in eating, so one of the effective parameters in eating is traced to color of the food, itself; It may be questioned in two ways: firstly, what causes one's perception of food refers to one's phantasm of smell and color of food is about phantasm that is similar among a group of people and is formed in their mind in a long term. Secondly, what makes a certain type of food good for a person is his experience of eating it and with a different color this experience feels inappropriate for him. Therefore, he would always like to register a fixed image of food in mind and prefer that his favorite color be manifested in some other places. Presented the suggestion for synchronizing the taste and color used in interiors of restaurants and coffee shops, dining tables, dishes with various applications, packaging and product design, since colors can improve tastes and have an intensive emotional effect on audiences. For example, yogurt served in blue dishes is judged to be sweeter than the same yogurt in black dishes [35]. On this basis, this research is focused on two main questions:

\section{Do colors impact people's perception of taste?}

2. Can we present a significant correlation between color and taste?

\section{Materials and Methods}

In this study, the taste of twelve colors having the highest aspect in foods and food packing was questioned. The questioned colors were classified in four groups; the first group includes the primary colors (yellow, red and blue), the second class is that of secondary colors such as purple, orange and green, the third group includes no-chroma colors (white, black, gray) and the forth group consists of brown and pink. The tastes were also classified in two groups: principal tastes including sour, salty, sweet, chilly and bitter. In this study, it is assumed that saturation, value and chroma of colors affect the answer. Also, according to the studies of Guilford and Smith, women have higher awareness of colors and their preferences in color selection are more various. So using one color name instead of a group of colors might increase the error percentage, and the color which people have in their minds might be different. According to that, images of colors with the same values and chroma and saturation on an average gray background were questioned from 112 people. We kept the proportion of men and women the same. Moreover, the population extent of information including age, gender and education was also evaluated in responded results. By showing the image of each color, people were able to select one or more choices from all the seven tastes for each color (Questionnaire (Figure 1)). Collecting the information by distributing questionnaires in different areas of Tehran was randomly done and the Excel software was used for data analysis and charts' outputs.

\section{Results}

\section{Statistical population study}

The characteristics of the study subjects are represented in Table 1. The number of males and females is the same. Moreover, their ages vary from 20 to 60 and they all have academic education.

\section{Selected taste for major colors}

Figure 2 illustrates the percentage of major colors (red, yellow and blue) for the statistic population of males and females. Blue is tasteless (35.27). Sweet is the second taste (24.53). Whereas female subjects associate blue with sweetness (31.03), male subjects associate blue with tastelessness (36.06). Sweetness has a high percentage for red (56.6). Both males and females assign the highest score to bitterness. Sweetness is in the second place (17.967). Males associate red with sweetness (23.07). The selected taste for yellow is sweet (31.32). Tastelessness has the second place (17.48). There is no a clear association between age and education on the one hand and the selected taste of each color on the other hand.

\section{Selected taste for secondary colors}

Figure 3 shows the selected tastes for the secondary colors: purple, orange and green. Generally, bitterness (20.74) and sourness (19.82) have the highest percentage for purple and their amounts are almost

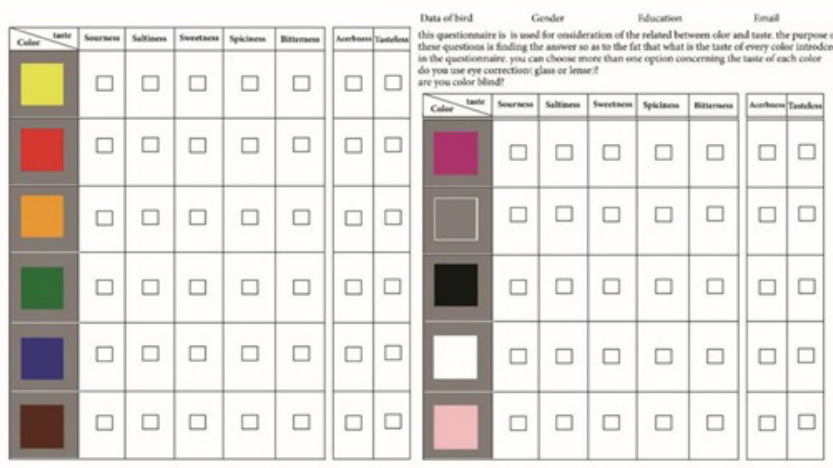

Figure 1: The questionnaire for color and taste used in this study.

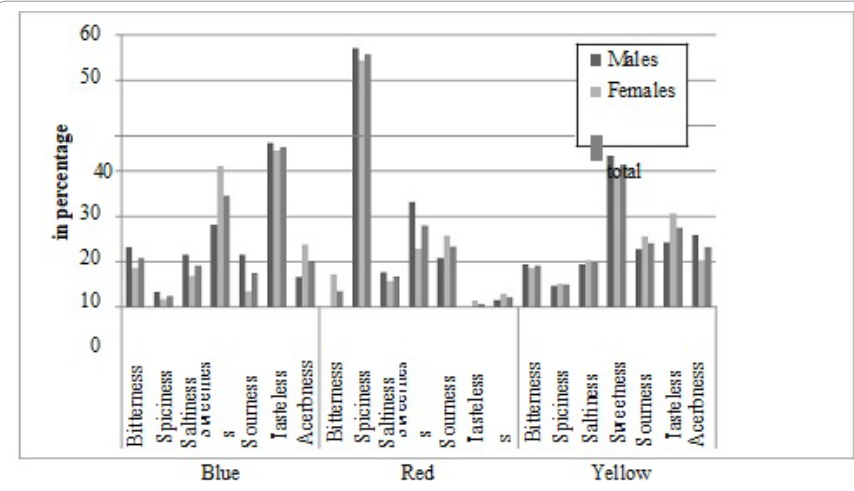

Figure 2: The preferences in taste for males and females in percentage of primary colors group. 
similar. Males have selected bitterness for purple (23.63). In addition, males and females assigned nearly similar scores to sourness. Therefore, a common pattern is presented for the selection females and 17.85 percent of females associated sweetness with purple which has the third place.

Orange has the highest scores for sourness (37.09) and sweetness (31.45), respectively. However, males assigned higher scores to sourness (41.93). Females allocated higher scores to sweetness (38.7). This indicates a meaningful pattern for the selection of males and females.

According to this study, green has the highest rate for tastelessness (23.55). Whereas sourness (18.73) and sweetness (17.02) come next with the same proportion. The result of answers with regard to selecting sourness and sweetness by males and females indicate a meaningful pattern in gender. Because females allocated the highest score to sweetness (22.58) and males assigned the similar score to sourness proportionally (22.95).

\section{Selected taste for brown and pink}

13.62 percent of subjects associated pink with sweetness. Tasteless was given the second place (21.92). The most selected taste for brown was bitterness. Both males and females selected it as the bitterest color. The statistics related to males and females are almost similar (Figures 4 and 5).

\section{Specific tastes for each color and effective factors}

Colors affect taste perception in various ways. These results are true for all the four groups. These results show meaningful relationships between primary colors, complementary colors and monochrome. The effect of color on taste is explained in different experiments ambiguously. Maga [27] states that red does not have a remarkable

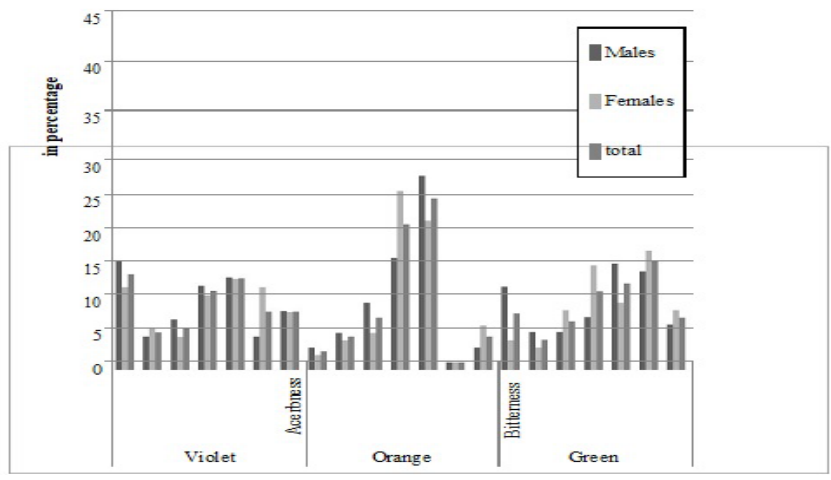

Figure 3: The preferences in taste for males and females in percentage of secondary colors group.

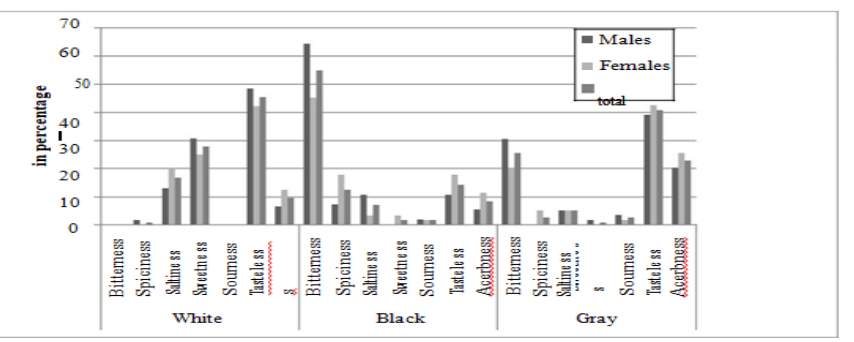

Figure 4: The preferences in taste for males and females in percentage of monochrome colors group. effect on sweetness. Most of the studies show the remarkable effect of red on sweetness perception [35-37]. Moreover, Lavin and Lawless [38] showed that dark red is sweeter than light red. Therefore, red has an effect on sweetness and selecting sweetness for red is in the second place.

Increasing green caused the reduction of sensitivity to sourness [27]. But in the present study green increases the sensitivity to sourness [37], was successful to repeat this finding and state that green decreases sweetness of foods, whereas it increases sourness in pear syrup. The statistics shows sourness of green. In the study of Lavin and Lawless [38], it was shown that light green is sweeter than dark green. In the present study, green also affects sweetness perception. In the studies of Maga [27], it was indicated that increasing yellow causes the decrease in sensitivity to sweetness and sourness. It is contradictory with the results of this study. Yellow affects more the perception of sourness and sweetness and indeed increases sourness and sweetness.

Moreover, most people cannot determine a color for saltiness. For instance, we can refer to pretzel (brown), potato chips (yellow), popcorn (white), olive (green and black) and gherkin (green) [38].

In the present study, this argumentation is also verified (refer to saltiness for each color in Figure 6). In the researches of Pangborn and Hansen [39], sourness is related to green in products which are not sour per se including green vegetables. In the present study, sour is in the third place for green.

The present study is related to investigating different tastes perceived via colors. In the previous studies, a meaningful relationship has not been shown between various tastes tailored to colors. Some of the experiments were conducted about the color effects on smell and taste of colored and colorless liquids or drinks. In these experiments, it seems that the subjects learn that the color of drink is different and

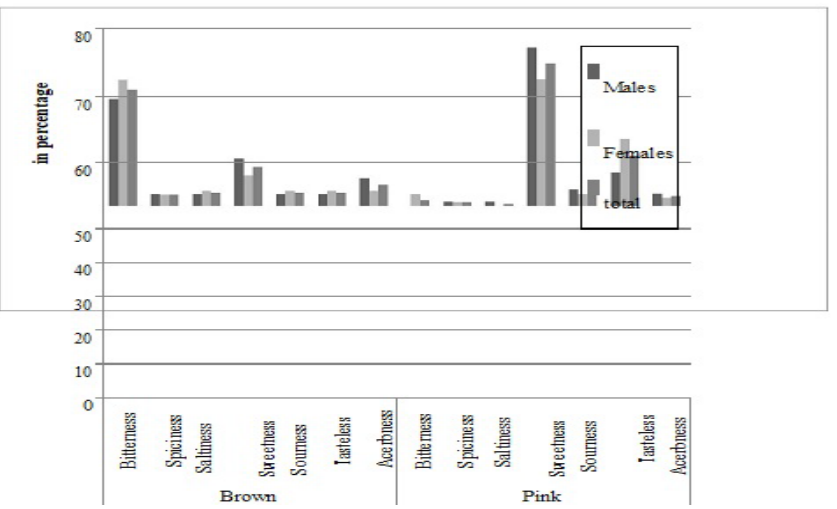

Figure 5: The preferences in taste for males and females in percentage of Brown and Pink.

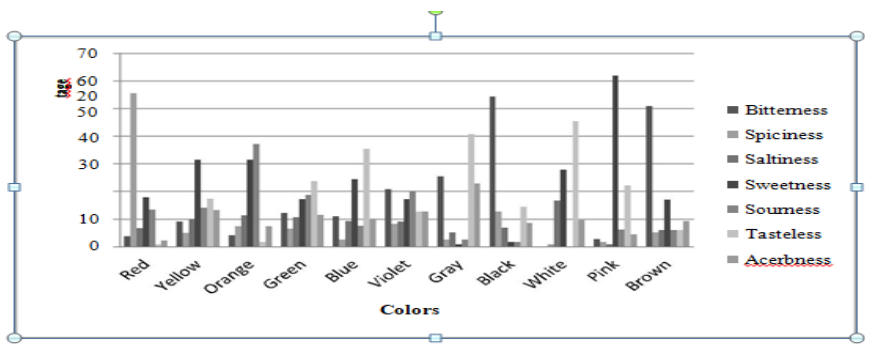

Figure 6: The preferences in taste for all color groups. 


\begin{tabular}{|c|c|c|}
\hline Characteristics & Number & Percentages \\
\hline \multicolumn{3}{|c|}{ Gender } \\
\hline Male & 56 & 50.0 \\
\hline Female & 56 & 50,0 \\
\hline Total & 112 & 100.0 \\
\hline Missing & 0 & 0 \\
\hline \multicolumn{3}{|c|}{ Age range } \\
\hline till 18 & 0 & 0 \\
\hline 19 till 25 incl. & 35 & 31.25 \\
\hline 26 till 35 incl. & 42 & 37.5 \\
\hline 36 till 45 incl. & 21 & 18.75 \\
\hline 56 till 65 incl. & 12 & 10.71 \\
\hline 66 and older & 2 & 1.78 \\
\hline Missing & 0 & 0 \\
\hline Total & 112 & 100.0 \\
\hline \multicolumn{3}{|c|}{ Education } \\
\hline University level & 51 & 45.53 \\
\hline Higher vocational level & 43 & 38.39 \\
\hline Lower vocational level & 16 & 14.28 \\
\hline Missing & 2 & 1.78 \\
\hline Total & 112 & 100.0 \\
\hline
\end{tabular}

Table 1: Characteristics of the study population.

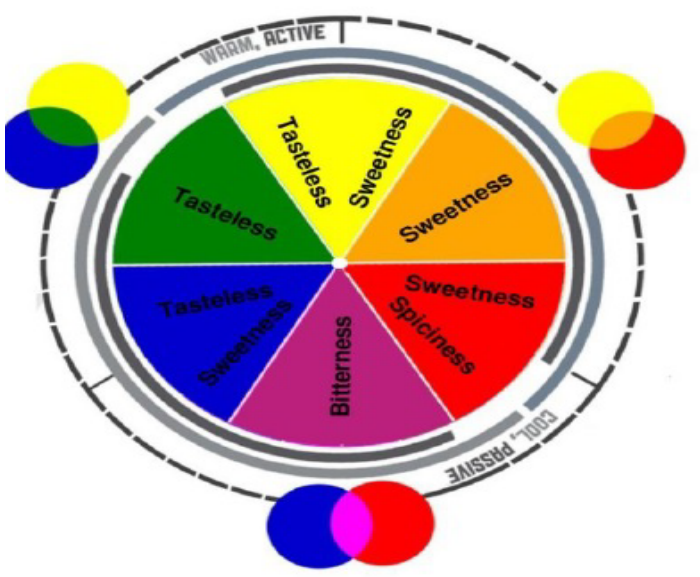

Figure 7: The rules for colors and tastes in color circle.

predict a special taste for each drink. Therefore, these experiments may bring about biases on behalf of the subjects. Moreover, most of the base colors were investigated in these kinds of experiments $[27,39]$. Thus, in these experiments a few stimuli were selected for assessments $[4,12,40]$. However, a limited number of stimuli seem to explain the color effect on taste and smell ambiguously. Since people try to identify the identities which were unspecified for them. Maga [27] stated that frequency and repetition of coloring simple liquids make the subjects expect a taste for the liquids. Therefore, they are eager to perceive a taste. In the present study, it is attempted to use questionnaires in order to prevent biases towards their perception and interests to identify liquids. Data analyses indicate that tastes of primary and secondary colors have a meaningful relationship with one another which overlaps with Itten's color cycle and color rules. As figure 6 shows, primary colors have their specific tastes and secondary colors present the common taste between primary colors created from their composition. For instance, yellow is sweet and tasteless. Red is bitter and sweet. Orange, composed of red and yellow, has thus the common taste between yellow and red which is sweet. This relationship is true for complementary color of green. Green is composed of yellow and blue. The common taste between these two colors is tasteless. In addition, green has the highest statistic in perceiving tastelessness. But statistical results about purple were not completely similar to complementary colors. Because purple is composed of red and blue and the common taste between these two primary colors is sweetness. Selecting sweetness for purple is in the third place after bitterness and sourness. Having identified the relationships between taste and color in the color circle, other color rules were investigated for each taste (Figure 7).

\section{Tint contrast}

According to Itten, tint contrast is the strongest between colors like black and white. Pure and initial colors have the strongest contrast. When secondary colors substitute primary colors, contrast decreases [41]. As statistics show black has a bitter taste and white is sweet. As a result, they have the strongest contrast in tastes (Figure 7).

\section{Dark and light contrast}

According to Itten, the most obvious contrast is related to black and white which are the most powerful ways of expression in painting. The most obvious contrast is between bitterness and sweetness (Figure 7).

There are numerous greys between black and white. Grey is neutral, indifferent and achromatic. It is easily affected by the opposite color. Moreover, it is mute and silent but can be transformed quickly. Grey acquires its color identity from other colors 43 .

\section{Discussion}

Comparing the results of this study with Itten's remarks, the same results can be achieved as for the taste of grey. Grey is tasteless, an indifferent taste which is quickly affected by other tastes. Tastelessness is silent; it is transformed quickly and acquires its life and identity from other tastes. If another taste is added to it, it will be transformed. One can feel an amount of heat by observing colors. The sense of coldness and heat depends on internal and mental factors. Yellow is the brightest color and purple is the darkest color in the color circle. These two colors have the most unusual contrast of black and white which are located along the circle's diameter and across each other. This is also true for tastes. These two colors have a high contrast in taste. Yellow and purple are sweet and bitter respectively and are located along the taste circle's diameter (Figure 7).

\section{Conclusion}

The participants' responses to the questions concerning taste color indicate a specific relationship between taste and color which overlaps with Itten color cycle and color rules. According to data analyses, main colors have their own specific tastes. Blue is associated with tastelessness (35.27). Sweetness is in the second place (24.53). Red has the highest score for bitterness (55.6) and sweetness is in the second place. The selected taste for yellow is sweet (31.32) and tastelessness is given the second place (17.48). These results have a meaningful relationship with secondary colors. The taste of secondary colors is the common taste between two primary mixed colors. Thus, orange which is composed of red and yellow has the common sweet taste between red and yellow. Green is created by mixing yellow and blue and their common taste is tastelessness. This taste has the highest score for green color. But the 
Citation: Fateminia M, Ghotbabadi TD, Azad KM (2018) Taste Laws in Color Wheel and its Impact on Food Packaging. J Food Process Technol 9: 739. doi: $10.4172 / 2157-7110.1000739$

Page 5 of 5

results related to purple are not completely similar to complementary colors. In the present study, some rules such as tint contrast and dark and light contrast is true for the contrast between the taste of black and white and yellow and purple. Regarding these results, using colors is effective in physical and psychological perception of taste. And personality traits like gender do not have a specific effect on identifying and recognizing the taste of colors.

\section{References}

1. Bayarri S, Calvo C, Costell E, Duran L (2001) Influence of color on perception of sweetness and fruit flavor of fruit drinks. Food Sci Technol Int 7: 399-404.

2. Zampini M, Sanabria D, Phillips N, Spence C (2007) The multisensory perception of flavor: Assessing the influence of color cues on flavor discrimination responses. Food Qual Prefer 18: 975-984.

3. Koza BJ, Cilmi A, Dolese M, Zellner DA (2005) Color enhances orthonasal olfactory intensity and reduces retronasal olfactory intensity. Chem Senses 30: 643-649.

4. Du Bose CN, Cardello AV, Maller O (1980) Effects of colorants and flavorants on identification, perceived flavor intensity, and hedonic quality of fruit-flavored beverages and cake. J Food Sci 45: 1393-1399.

5. Posner MI, Nissen MJ, Klein RM (1976) Visual dominance: An informationprocessing account of its origins and significance. Psychol Rev 83: 157-171.

6. Partan S, Marler P (1999) Communication goes multimodal. Science 283 1272-1273.

7. Alley RL, Alley TR (1998) The influence of physical state and color on perceived sweetness. J Psychol 132: 561-568.

8. Christensen C (1985) Effect of color on judgments of food aroma and food intensity in young and elderly adults. Perception 14: 755-762.

9. Frank R, Ducheny K, Mize S (1989) Strawberry odor, but not red color enhances the sweetness of sucrose solutions. Chem Senses 14: 371-377.

10. Koch C, Koch EC (2003) Preconceptions of taste based on color. J Psychol 137: 233-242.

11. Blackwell L (1995) Visual clues and their effects on odour assessment. Nutr Food Sci 5: 24-28.

12. Morrot G, Brochet F, Dubourdieu D (2001) The color of odors. Brain Lang 79 : 309-320

13. Zellner DA, Kautz MA (1990) Color affects perceived odor intensity. J Exp Psychol Hum Percept Perform 16: 391-397.

14. Davis RG (1981) The role of nonolfactory context cues in odor identification. Percept Psychophys 30: 83-89.

15. Zellner DA, Whitten LA (1999) The effect of color intensity and appropriateness on color-induced odor enhancement. Am J Psychol 112: 585-604.

16. Engen T (1972) The effect of expectation on judgments of odour. Acta Psychol 36: $450-458$.

17. Ou LC, Luo MR (2004) A study of color emotion and color preference. I. Color emotions for single colors. Color Res Appl 29: 232-240.

18. Eysenck HJ (1941) A critical and experimental study of color preferences. Am J Psychol 54: 385-394.
19. Saccucci O (2005) Does gender effect how people taste sugar? 2: 1.

20. Dittmar M (2001) Changing color preferences with ageing: A comparative study on younger and older native germans aged 19-90 years. Gerontology 47: 219226.

21. Saito M (1996) Comparative studies on color preferences in Japan and othe Asian regions with special emphasis on the preference for white. Color Res Appl 21: 35-49.

22. Hutchings JB (1999) Food, color and appearance. ( $2^{\text {nd }}$ edtn), Aspen publishers Maryland.

23. Crozier WR (2002) The psychology of color preferences, in Color.

24. Johnson J, Clydesdale FM (1982) Perceived sweetness and redness in colored sucrose solutions. J Food Sci 47: 747-752.

25. Oram N, Laing DG, Hutchinson I, Owen J, Rose G, et al. (1995) The influence of flavor and color on drink identification by children and adults. Dev Psychobio 28: 239-246.

26. Maga JA (1974) Influence of color on taste thresholds. Chem Senses Flavor 1: 115-119.

27. Kwallek N, Lewis CM, Lin-Hsiao JW, Woodson H (1996) Effects of nine monochromatic office interior colors on clerical tasks and worker mood. Color Res Appl 21: 448-458.

28. Zajonc RB (1980) Feeling and thinking, preferences need no inferences. Am Psychol 35: 151-175.

29. Charles AR II (1995) Color codes: Modern theories of color in philosophy, painting and architecture, literature, music, and psychology. UPNE.

30. Moir HC (1936) Some observations on the appreciation of flavour in foodstuffs J Soc Chem Ind 14: 145-148

31. Duncker K (1939) The influence of past experience upon perceptual properties Am J Psychol 52: 255-265.

32. Oropesa RS (1995) Consumer possessions, consumer passions, and subjective well-being. Sociol Forum 10: 215-244.

33. Hall RL (1958) Flavor research and food acceptance: A survey of the scope of flavor and associated research, compiled from papers presented in a series of symposia given in 1956-1957. Reinhold, New York.

34. Caron G (1992) Un Carré Noir Dans Le Design, Dunod, Paris.

35. Strugnell C (1997) Colour and its role in sweetness perception. Appetite 28: 85

36. Pangborn RM (1960) Influence of color on the discrimination of sweetness. Am J Psychol 73: 229-238.

37. Kostyla AS (1978) The psychophysical relationships between color and flavo of some fruit flavored beverages. University of Massachusetts, Amherst.

38. Lavin J, Lawless H (1998) Effects of color and odor on judgments of sweetness among children and adults. Food Qual Prefer 9: 283-289.

39. Pangborn RM, Hansen B (1963) The influence of color on discrimination of sweetness and sourness in pear-nectar. Am J Psychol 76: 315-317.

40. Hoegg J, Alba JW (2007) Psycholinguistic phenomena in marketing communications. Erlbaum, Mahwah.

41. Johannes I (1993) The art of color: The subjective experience and objective rationale of color. John Wiley \& Sons Inc 2: 1. 